\title{
Synthesis and Structure of Nanocomposites based on Linear Polymers and Nanoparticles of Titanium Dioxide
}

\author{
Elena Kuznetsova ${ }^{1}$, Tran Quyet Thang ${ }^{2}$, \\ ${ }^{1}$ Moscow Aviation Institute (National Research University), \\ Moscow, Volokolamskoe shosse, 4, 125993, \\ Russia \\ ${ }^{2}$ Le Quy Don Technical University \\ Hanoi, 236 Hoang Quoc Viet, \\ Vietnam
}

Received: February 19, 2021. Revised: August 20, 2021. Accepted: September 10, 2021. Published: September 13, 2021.

\begin{abstract}
Nanocomposites based on titanium dioxide and epoxy polymer nanoparticles have been obtained and investigated by the in situ method at the stage of curing with preliminary ultrasonic dispersion and evacuation. The composition and structure of the obtained $\mathrm{TiO}_{2}$ nanocomposites have been studied by IR spectroscopy and scanning electron microscopy. It is shown that with an increase in the content of nanoparticles, their average size increases to $88 \mathrm{~nm}$ at a $\mathrm{TiO}_{2}$ concentration of $1 \%$ as a result of secondary aggregation processes.
\end{abstract}

Keywords-Nanocomposites, polymers, nanoparticles, titanium dioxide.

\section{INTRODUCTION}

$\mathrm{T}$ O improve the existing and introduce new properties of the matrix, it is often reinforced with various fillers. The addition of micro-sized particles often has a negative effect on some properties, for example, impact strength. A new approach to solving this problem is associated with nanotechnology and the use of fillers on the nanometer scale [1]-[9]. Nanoparticles embedded in a polymer matrix are attracting more and more interest due to the unique mechanical, optical, electrical, magnetic, and other properties exhibited by nanocomposites [10]-[17]. Due to the nanometer size of these particles, their physicochemical characteristics differ significantly from those of molecular materials. Nanoparticle-reinforced polymers combine the properties of both the main polymer matrix and discrete nanoparticles. By controlling parameters such as the rate of rejection and the amount of nanoparticles, the final properties of the nanocomposite can be influenced [18]-[25].

Modern composites have not only a wide range of physical and mechanical properties, but are also capable of directionally changing them, for example, increasing fracture toughness, regulating rigidity, strength, and other properties. These possibilities are expanded when fibers of different nature and geometry are used in composites, i.e., when creating hybrid composites. In addition, these materials are characterized by the appearance of a synergistic effect (coordinated joint action of several factors in one direction).

Nanoparticles, even with a very low volumetric content (less than $1 \%$ ), are contained in such a fragment in a very large amount, and it is impossible to model their effect at this scale level. For example, a cubic fragment of a $1 \mu \mathrm{m}$ matrix contains more than thousand nanoparticles for a given volumetric content. Therefore, in particular, the nano-modified binder is white, while the usual binder is yellow. To model such materials, it is necessary to resort to multiscale approaches and to carry out a consistent determination of effective properties at various scale levels. This task is greatly simplified if the properties of the nanomodified matrix are known from experiments. In particular, it is known that its Young's modulus is $2.5 \mathrm{GPa}$. The missing characteristic is Poisson's ratio, which can be approximately taken unchanged, or estimated on the basis of analytical calculations using the found value of the "effective" volumetric content of the filler, which was done. Further, it suffices to numerically solve the averaging problem on a representative fragment containing only nanoparticles.

The properties of the interface or interfacial zone, first of 
all, the adhesive interaction between the fiber and the matrix, determine the level of properties of composites and their retention during operation. Local stresses in the composite reach their maximum values just near or directly at the interface, where material destruction usually begins. The interface must have certain properties to ensure efficient transfer of the mechanical load from the matrix to the fiber. The adhesion bond at the interface should not be destroyed under the action of thermal and shrinkage stresses arising from the difference in the temperature coefficients of linear expansion of the matrix and fiber or as a result of chemical shrinkage of the binder during its curing.

When creating nanocomposites, the key tasks are the development of efficient, reliable, and affordable production technologies for mass production, which make it possible to obtain materials with stable characteristics. The hand lay technique, also called wet lay, is the simplest and most widely used process for producing flat reinforced composites. The process consists of laying layers of a polymer in successive layering using an epoxy matrix. Wet-laying is a molding process that combines layers of reinforced carbon fiber with epoxy to create a high-quality laminate. Before starting the installation process, you must prepare the appropriate form. This preparation consists of cleaning the table and applying a release agent to the surface. The manual laying process can be divided into four main steps: mold preparation, epoxy coating, laying and curing. Form preparation is one of the most important steps in the installation process. This process requires dry reinforcement layers and the application of a wet epoxy matrix. They are connected together - reinforcing material, impregnated with a matrix - epoxy resin.

Titanium dioxide $\left(\mathrm{TiO}_{2}\right)$ is one of the promising materials as a nanofiller due to its optical, thermal, photocatalytic and electrophysical properties. The application potential of nanodispersed $\mathrm{TiO}_{2}$ is very high: titanium dioxide and materials based on it can be used as an additive in plastics, an ultraviolet light blocker, an energy converter in solar batteries, an agent for photocatalytic degradation of bacteria and photochemical degradation of toxic chemicals, for wastewater treatment. Due to their chemical inertness, low toxicity, photocatalytic activity, high refractive index and other beneficial properties, titanium dioxide nanoparticles have attracted the attention of many researchers and are used in the food, paint and varnish industry, etc. Previous studies have shown that the introduction of $\mathrm{TiO}_{2}$ nanoparticles improves some properties of epoxy resin. But the process of interaction and the mechanism of hardening of epoxy resin are not fully understood. There are few works on epoxy nanocomposites with $\mathrm{TiO}_{2}$ nanoparticles; therefore, it is relevant to obtain new examples of such nanocomposites and study their physical and mechanical properties, since due to the presence of $\mathrm{TiO}_{2}$, it is possible to use such nanocomposites in biomedicine, as bactericidal and photocatalytic surfaces. The aim of this work is to create an epoxy nanocomposite based on $\mathrm{TiO}_{2}$ nanoparticles and to study its physical and mechanical properties depending on the concentration of nanoparticles.

The matrix can be a thermosetting polymer - epoxy resin, which has already found many applications: from structural composites to adhesives and surface coatings. Epoxy resins already have a number of unique qualities among polymers: no shrinkage during curing, high adhesion to various substrates, good dielectric and other valuable properties [36]-[64]. Nanocomposites using thermoplastic polymers are well known and studied to improve mechanical, electrical, thermal and insulating properties. However, nanocomposites using thermosetting polymers have not been studied as widely, especially using $\mathrm{TiO}_{2}$.

Nanoparticles are usually introduced into the polymer matrix using various methods. Dispersion processes are necessary in order to transfer nanoparticles from an agglomerated state to a uniformly dispersed state [26]-[34]. The most popular are live streaming with the use of chemical methods and the use of high shear forces in the process of mechanical dispersion of the powder. Chemical methods are capable of generating individual and non-agglomerated nanoparticles within a thermosetting or thermoplastic polymer. For mechanical dispersion, ultrasonic treatment is often used, which also improves the dispersion state of nanoparticles.

\section{METHODS FOR PREPARING $\mathrm{TIO}_{2}$-BASED NANOCOMPOSITES}

Methods for the synthesis of nanocomposite materials (or nanocomposites) are divided into two main large approaches: in situ and ex situ. The creation of nanocomposites by the in situ method makes it possible to simultaneously (in one stage) obtain both a matrix and nanoparticles, obtaining a nanocomposite at the output. The advantage of the method is that it prevents particle agglomeration while maintaining a good spatial distribution in the polymer matrix. The main disadvantage of the method is that all the products of the synthesis of nanoparticles remain in the nanocomposite, which can deteriorate the quality and purity of the obtained material.

When using the ex situ method, each stage of nanocomposite creation is brought into a separate process: from the synthesis of nanoparticles to the preparation of a nanocomposite. This method is more energy and labor intensive compared to in situ, and requires much more time. Also, special attention should be paid to the dispersion of the nanocomponent in the matrix, since during long-term storage nanoparticles are collected into larger ones and they must be dispersed by various methods, for example, by ultrasonic treatment [1]-[8]. The ex situ synthesis method is more suitable for large scale industrial applications than the in situ method.

The ex situ method, despite all its drawbacks, is used more often than the more technologically advanced in situ method. First of all, this is due to the simplicity of the approach based on the fact that in such reactions the synthesis of nanoparticles is not complicated by additional reactions with the polymer matrix, the resulting nanocomposite will not contain byproducts associated with the formation of nanoparticles in the 
polymer matrix, etc.

\section{STRUCTURE AND PROPERTIES OF $\mathrm{TIO}_{2}$-BASED NANOCOMPOSITES}

The structure of nanocomposites, as well as properties, directly depend on many factors, such as: the type of particlematrix bond, mass composition, modification of the particle surface, size and dispersion of particles in the matrix, etc. As a result of composite synthesis, the properties of the matrix can improve, deteriorate, or acquire new properties.

Polymer nanocomposites reinforced with inorganic nanoparticles attract considerable interest due to their light weight, low cost, and controlled physical and mechanical properties. They find their application from the paint and varnish industry to the aviation and aerospace industries. For their practical application, it is necessary to create new materials based on them with the necessary physical and mechanical characteristics. In this regard, studies aimed at improving the mechanical and functional properties of nanocomposite materials based on epoxy polymers and revealing the role of nanofillers in providing the required characteristics are important.

Nanocomposites based on $\mathrm{TiO}_{2} /$ epoxy polymer nanoparticles were obtained by the in-situ method at the stage of curing an epoxy resin with pre-dispersed titanium (IV) oxide nanoparticles in an epoxy resin matrix. To improve the dispersion of the introduced nanoparticles in a viscous epoxy resin, we used the method of ultrasonic treatment at a frequency of $40 \mathrm{kHz}$ for $10 \mathrm{~min}$. The curing process was carried out in a two-stage temperature conditions at $90{ }^{\circ} \mathrm{C}-3$ h, $160{ }^{\circ} \mathrm{C}-3 \mathrm{~h}$.

The elemental composition of the obtained nanocomposites was investigated using energy dispersive X-ray spectroscopy. The X-ray diffraction pattern of the synthesized nanocomposites (Figure 1) showed the presence of crystalline structures. Diffraction peaks are narrow with high intensity.

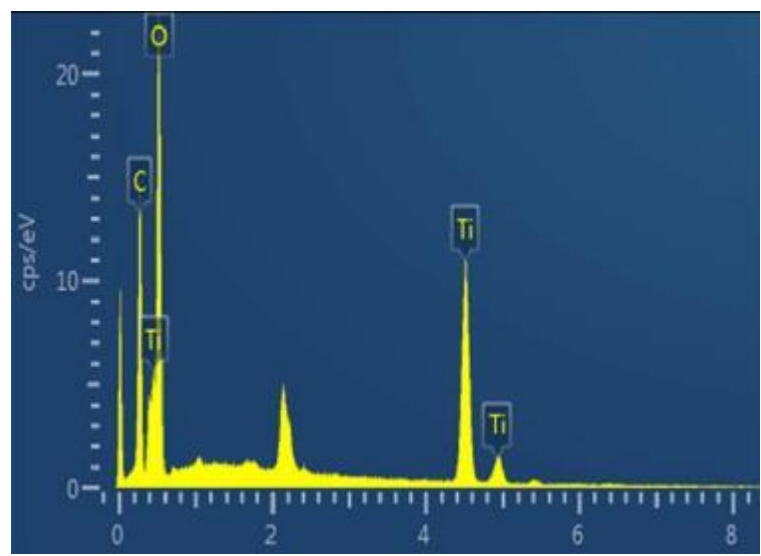

Fig. 1 edrs spectrum of $\mathrm{TiO}_{2} / \mathrm{EP}$ nanocomposite.

As the data shows, no titanium oxide was found in the pure epoxy film (Figure 2), which confirms its purity (results presented are expressed as percent by weight). The opposite is shown by the results of analyzes of nanocomposite samples containing titanium dioxide (Figure 3,4). The data obtained make it possible to assert the presence of titanium dioxide in the samples.

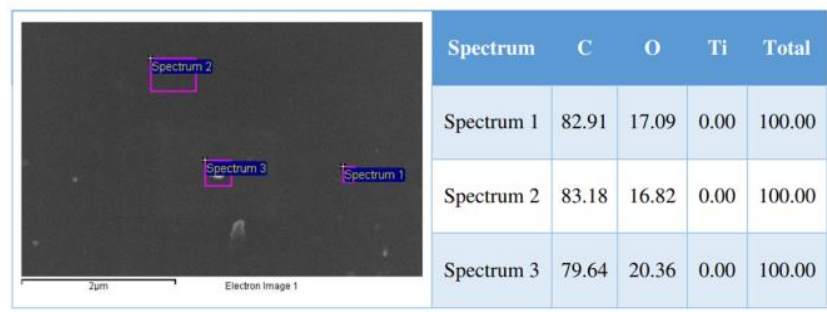

Fig. 2 edrs results for a pure epoxy sample.
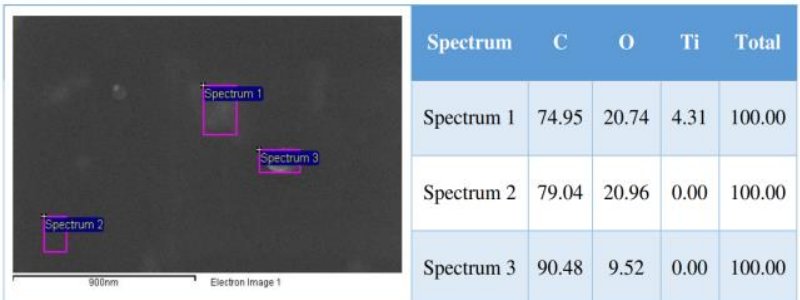

Fig. 3 edrs results for $\mathrm{TiO}_{2} / \mathrm{EP}$ composite with titanium mass content of $0.5 \%$.
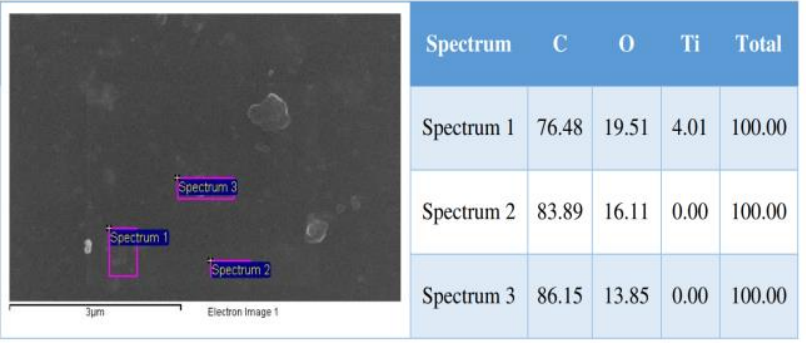

Fig. 4 edrs results for $\mathrm{TiO}_{2} / \mathrm{EP}$ composite with $1 \%$ titanium mass content

Further research was carried out on a Fourier transform spectrophotometer, which turned out to be more indicative in our study. Figure 5 shows the absorption spectra for pure titanium dioxide, pure epoxy resin and nanocomposites with a mass content of $1 \%$ and $4 \%$ nanofiller.

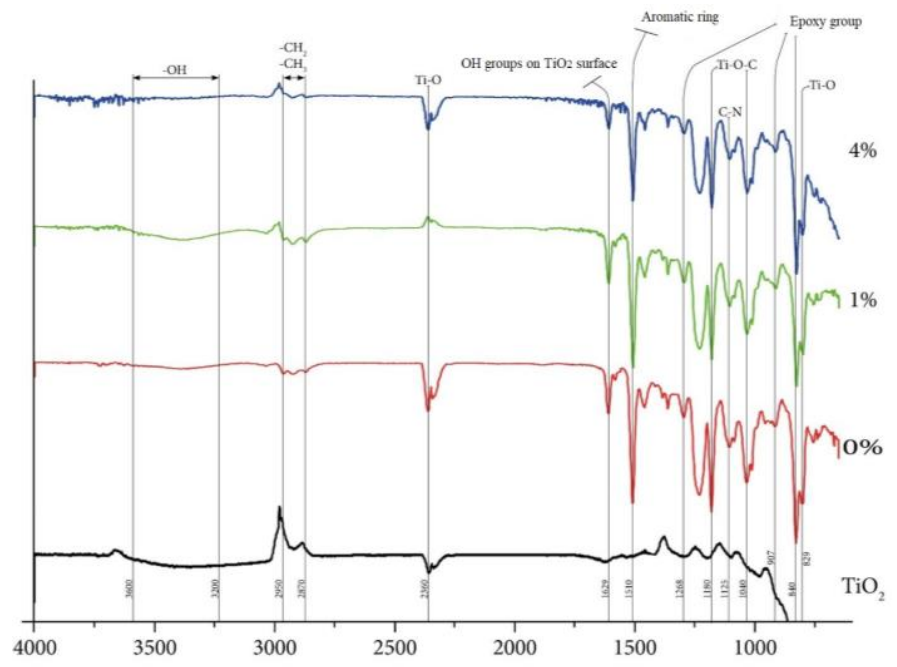


Fig. 5 Absorption spectra of IR spectroscopy with Fourier transform

for samples containing $4 \%, 1 \%$ and $0 \% \mathrm{TiO}_{2}$ and pure $\mathrm{TiO}_{2}$.

In the region of $3600-3200 \mathrm{~cm}^{-1}$, one broad weakly pronounced absorption band of stretching vibrations of $-\mathrm{OH}$ groups of the matrix is observed, and hydroxyl groups on the surface of $\mathrm{TiO}_{2}$ particles can also appear here. The -OH groups also include the peak at $1629 \mathrm{~cm}^{-1}$, some literature indicates that the peak at $1629 \mathrm{~cm}^{-1}$ also indicates the presence of hydroxyl groups on the surface of titanium dioxide. Adsorbed $-\mathrm{OH}$ ions play a central role in photocatalysis as they capture charge carriers to produce reactive $-\mathrm{OH}$ radicals, which are the driving force behind the photocatalytic process. In addition, they act as adsorbents for pollutant molecules. The epoxy groups of the matrix manifest themselves at weakly pronounced peaks at $840,907 \mathrm{~cm}^{-1}$ (valence asymmetric) and $1268 \mathrm{~cm}^{-1}$ (valence symmetric). This indicates that after curing, a small amount of unopened rings remains during the polymerization reaction of epoxy groups. Vibrations of the $-\mathrm{NH}-$ group are not manifested, since nitrogen becomes tertiary as a result of the reaction and manifests itself in stretching vibrations of $\mathrm{C}-\mathrm{N}$ bonds at a peak of $1125 \mathrm{~cm}^{-1}$, which indicates a past polycondensation reaction between the hardener and epoxy groups. A number of weak peaks in the range of $2950-2870 \mathrm{~cm}^{-1}$ are attributed to symmetric and asymmetric vibrations of the $-\mathrm{CH}_{2}$ and $-\mathrm{CH}_{3}$ groups. In addition, some signals in the $1295-1180 \mathrm{~cm}^{-1}$ region indicate the presence of aliphatic chains. Stretching vibrations $-\mathrm{C}=\mathrm{C}-$ of aromatic rings of diaminodiphenylmethane manifest themselves as a peak at $1510 \mathrm{~cm}^{-1}$. The $\mathrm{Ti}-\mathrm{O}$ bond manifests itself at peaks at $892 \mathrm{~cm}^{-1}$, and partially coincides with the vibrations of epoxy groups, and $2360 \mathrm{~cm}^{-1}$, and this region can be enhanced by the $\mathrm{Ti}-\mathrm{O}-\mathrm{C}$ bond, which manifests itself at $1180 \mathrm{~cm}^{-1}$. The $\mathrm{Ti}-\mathrm{O}-\mathrm{C}$ bond also appears as a peak at $1040 \mathrm{~cm}^{-1}$. According to some sources, the broad peak at $1230 \mathrm{~cm}^{-1}$ refers to pure titanium dioxide. In addition, according to the literature, in the region less than 750 $\mathrm{cm}^{-1}$ inaccessible on the graph, there are peaks of the $\mathrm{O}-\mathrm{Ti}-$ $\mathrm{O}$ bond at $692 \mathrm{~cm}^{-1}$ and the $\mathrm{Ti}-\mathrm{O}$ bond at 485 and $435 \mathrm{~cm}^{-1}$.

The structure of the obtained nanocomposites was studied using scanning electron microscopy, and histograms of the particle size distribution were plotted. In addition to the study of the obtained samples, a control study of pure $\mathrm{TiO}_{2}$ was done (Figure 6). The micrograph shows a large number of spherical nanoparticles. The data confirm that the nanoparticles have an average diameter of $46 \mathrm{~nm}$.
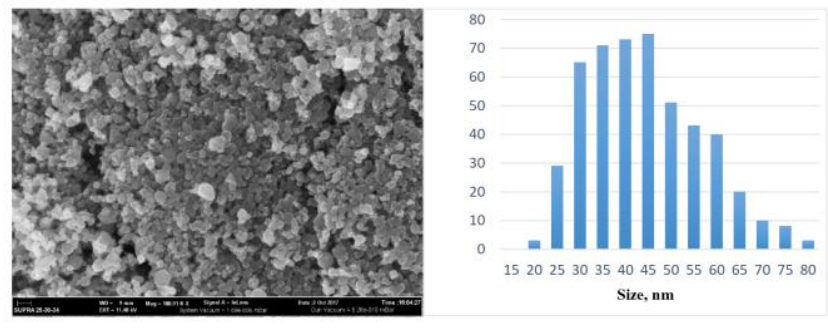

Fig. 6 sem image (left) and histogram of particle distribution (right) in the original $\mathrm{TiO}_{2}$.

In the nanocomposite containing $0.2 \% \mathrm{TiO}_{2}$ nanoparticles, aggregates of particles are observed, and therefore the average diameter increases from $46 \mathrm{~nm}$ to $64 \mathrm{~nm}$ (Figure 7). The micrograph shows single rounded particles, the distribution of particles is uniform.
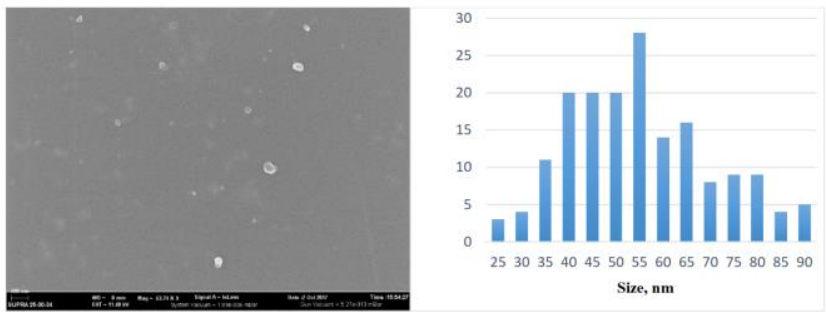

Fig. 7 sem image (left) and histogram of particle distribution (right) in a nanocomposite containing $0.2 \% \mathrm{TiO}_{2}$.

In the sample containing $0.5 \% \mathrm{TiO}_{2}$ based on the total mass (Figure 8), an increase in the average particle diameter up to $79 \mathrm{~nm}$ is also observed. The image shows clear individual rounded particles as well as small aggregates. No irregular accumulations of particles are observed.
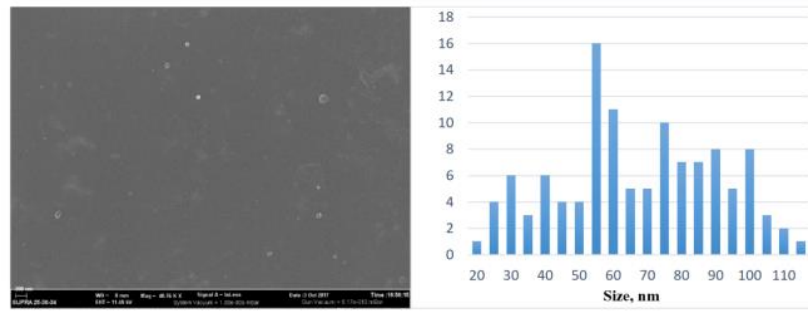

Fig. 8 sem image (left) and histogram of particle distribution (right) in a nanocomposite containing $0.5 \% \mathrm{TiO} 2$.

In the $\mathrm{TiO}_{2} / \mathrm{EP}$ nanocomposite with a nanoparticle content of $1 \%$ of the total mass (Figure 9), the growth trend of nanoparticles continues: the average diameter is $88 \mathrm{~nm}$. The micrograph shows a good distribution of particles, as well as the formed aggregates.
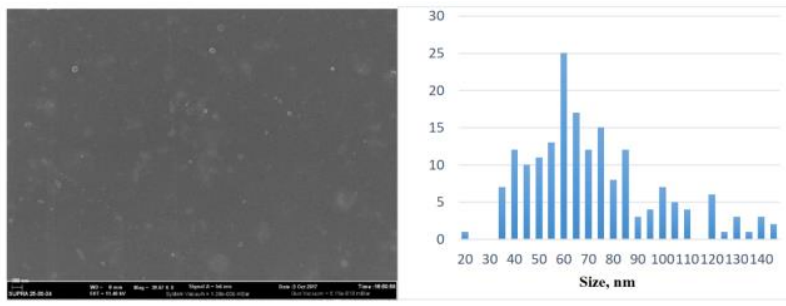

Fig. 9 sem image (left) and histogram of particle distribution (right) in a nanocomposite containing $1 \% \mathrm{TiO} 2$.

As the data show, with an increase in the concentration of the nanocomponent, the particle size also grows (from 46 to 88 $\mathrm{nm}$ at $1 \%$ of the nanocomponent). Obviously, with an increase in the concentration of the nanocomponent in the matrix, the distance between the particles decreases, which increases the 
probability of the formation of aggregates - the closer the particles are located to each other, the easier to them to overcome the disjoining forces caused by polymer molecules. Perhaps this problem can be solved by choosing the parameters of ultrasonic dispersion. To determine the structure of the obtained nanocomposite, the method of IR spectroscopy can be further used. IR spectroscopy allows first to get evidences of the interaction between nanoparticles and polymer matrix and, second, get the information about the structure of the resulting nanocomposite. For the details of the IR characterization of the polymer nanocomposites, it is referred to the literature [48]-[50].

\section{CONCLUSION}

$\mathrm{TiO}_{2} / \mathrm{EP}$ nanocomposites were prepared and investigated by the in situ method at the stage of curing in the presence of 4,4diaminodiphenylmethane with preliminary ultrasonic dispersion and evacuation. The composition and structure of $\mathrm{TiO}_{2} / \mathrm{EP}$ nanocomposites have been studied. It was shown that with an increase in the content of nanoparticles, their average size increases to $88 \mathrm{~nm}$ at a $\mathrm{TiO}_{2}$ concentration of $1 \%$ as a result of secondary aggregation processes. This opens new prospective for tailored fabrication of polymer nanocomposites with desired structure and properties. Further research can be aimed toward the development of nanocomposites with advanced mechanical properties.

\section{ACKNOWLEDGMENT}

This work was supported by the Russian Foundation for Basic Research (RFBR), projects № 19-08-01023a and 20-0800707.

\section{REFERENCES}

[1] O. A. Butusova, "Surface Modification of Titanium Dioxide Microparticles Under Ultrasonic Treatment, International Journal of Pharmaceutical Research, vol. 12, i. 4, pp. 2292-2296, 2020.

[2] O. A. Butusova, "Adsorption Behaviour of Ethylhydroxyethyl Cellulose on the Surface of Microparticles of Titanium and Ferrous Oxides," International Journal of Pharmaceutical Research, vol. 12, Supplementary Issue 2, pp. 1156-1159, 2020.

[3] M. O. Kaptakov, "Effect of Ultrasonic Treatment on Stability of $\mathrm{TiO} 2$ Aqueous Dispersions in Presence of Water-Soluble Polymers," International Journal of Pharmaceutical Research, vol. 12, Supplementary Issue 2, pp. 1821-1824, 2020.

[4] Yu. V. Ioni, "Synthesis of Metal Oxide Nanoparticles and Formation of Nanostructured Layers on Surfaces under Ultrasonic Vibrations," International Journal of Pharmaceutical Research, vol. 12, Issue 4, pp. 3432-3435, 2020.

[5] Yu. V. Ioni., "Effect of Ultrasonic Treatment on Properties of Aqueous Dispersions of Inorganic and Organic Particles in Presence of Water-Soluble
Polymers," International Journal of Pharmaceutical Research, vol. 12, Issue 4, pp. 3440-3442, 2020.

[6] N. A. Bulychev, A. V. Ivanov, "Study of Nanostructure of Polymer Adsorption Layers on the Particles Surface of Titanium Dioxide," International Journal of Nanotechnology, vol. 16, nos. 6/7/8/9/10, pp. $356-365$, 2019.

[7] O. A. Butusova, "Design and Properties of Magnetically Controlled Sorbents," Turkish Journal of Computer and Mathematics Education (TURCOMAT), vol. 12, no. 5, pp. 515-519, 2021.

[8] O. A. Butusova, "Application of Magnetically Controlled Sorbents for Detoxication," Turkish Journal of Computer and Mathematics Education (TURCOMAT), vol. 12, no. 5, pp. 520-524, 2021.

[9] L. N. Rabinskii, O. V. Tushavina, "Composite Heat Shields in Intense Energy Fluxes with Diffusion," Russian Engineering Research, 39(9), pp. 800-803, 2019.

[10] L. N. Rabinskiy, O. V. Tushavina, "Investigation of the influence of thermal and climate effects on the performance of tiled thermal protection of spacecraft," Periodico Tche Quimica, 16(33), pp. 657-667, 2019.

[11] V. N. Dobryanskiy, L. N. Rabinskiy, O. V. Tushavina, "Experimental finding of fracture toughness characteristics and theoretical modeling of crack propagation processes in carbon fiber samples under conditions of additive production," Periodico Tche Quimica, 16(33), pp. 325-336, 2019.

[12] B. A. Antufev, E. L. Kuznetsova, L. N. Rabinskiy, O. V. Tushavina, "Investigation of a complex stress-strain state of a cylindrical shell with a dynamically collapsing internal elastic base under the influence of temperature fields of various physical nature," Asia Life Sciences, (2), pp. 689-696, 2019.

[13] O. A. Pashkov, "Influence of Polymer Coatings on the Mechanical Properties of Steel Samples in Tensile and Bending Tests," Turkish Journal of Computer and Mathematics Education (TURCOMAT), vol. 12, no. 5, pp. 542-548, 2021.

[14] O. A. Pashkov, "Investigation of the Effect of Steel Plate Size and Elevated Temperature on Critical Load in Stability Tests," Turkish Journal of Computer and Mathematics Education (TURCOMAT), vol. 12, no. 10, pp. 1657-1663, 2021.

[15] Y. Sun, O. V. Egorova, E. L. Kuznetsova, "Identification of the front angle of a plane acoustic oblique pressure wave on convex surfaces with the use of analytical solution," Journal of the Balkan Tribological Association, 27(2), pp. 189-197, 2021.

[16] O. A. Pashkov, "Theoretical calculation of the thickness of interphase zones in the Al-Al2O3 composite," Turkish Journal of Computer and Mathematics Education (TURCOMAT), vol. 12, no. 10, pp. 1672-1677, 2021.

[17] O. A. Pashkov, "Experimental and Theoretical Study of Mechanical Properties of Matrix Composite Materials," Turkish Journal of Computer and Mathematics Education (TURCOMAT), vol. 12, no. 10, pp. 1678-1684, 2021. 
[18]L. N. Rabinskiy, S. A. Sitnikov, "Development of technologies for obtaining composite material based on silicone binder for its further use in space electric rocket engines," Periodico Tche Quimica, 15(Special Issue 1), pp. 390-395, 2018.

[19] B. A. Garibyan, "Determination of the Elastic Modulus of the Coating Using a Spherical Indenter," Turkish Journal of Computer and Mathematics Education (TURCOMAT), vol. 12, no. 10, pp. 1594-1600, 2021.

[20]B. A. Garibyan, "Theoretical Estimations of Influence of Polymer Coatings on the Elastic Modulus and Ultimate Strength of Steel Samples," Turkish Journal of Computer and Mathematics Education (TURCOMAT), vol. 12, no. 10, pp. 1651-1656, 2021.

[21] O. A. Butusova, "Stabilization of Carbon Microparticles by High-Molecular Surfactants," International Journal of Pharmaceutical Research, vol. 12, Supplementary Issue 2, pp. 1147-1151, 2020.

[22] Yu. V. Ioni, A. Ethiraj, "New Tailor-Made Polymer Stabilizers for Aqueous Dispersions of Hydrophobic Carbon Nanoparticles," International Journal of Pharmaceutical Research, vol. 12, i. 4, pp. 3443-3446, 2020.

[23] Yu. V. Ioni, "Nanoparticles of noble metals on the surface of graphene flakes," Periodico Tche Quimica, vol. 17, no. 36, pp. 1199-1211, 2020.

[24] O. A. Butusova, "Vinyl Ether Copolymers as Stabilizers of Carbon Black Suspensions," International Journal of Pharmaceutical Research, vol. 12, Supplementary Issue 2, pp. 1152-1155, 2020.

[25] M. O. Kaptakov, "Catalytic Desulfuration of Oil Products under Ultrasonic Treatment," International Journal of Pharmaceutical Research, vol. 12, Supplementary Issue 2, pp. 1838-1843, 2020.

[26]B. A. Garibyan, "Enhancement of Mechanical Properties of Inorganic Glass under Ultrasonic Treatment," International Journal of Pharmaceutical Research, vol. 12, Supplementary Issue 2, pp. 1829-1832, 2020.

[27]M. O. Kaptakov, "Enhancement of Quality of Oil Products under Ultrasonic Treatment," International Journal of Pharmaceutical Research, vol. 12, Supplementary Issue 2, pp. 1851-1855, 2020.

[28]A. N. Tarasova, "Vibration-based Method for Mechanochemical Coating Metallic Surfaces," International Journal of Pharmaceutical Research, vol. 12, Supplementary Issue 2, pp. 1160-1168, 2020.

[29]B. A. Garibyan, "Mechanical Properties of Electroconductive Ceramics," International Journal of Pharmaceutical Research, vol. 12, Supplementary Issue 2, pp. 1825-1828, 2020.

[30] Yu. V. Ioni, A. Ethiraj, "Study of Microparticles Surface Modification by Electrokinetic Potential Measuring," International Journal of Pharmaceutical Research, vol. 12, i. 4, pp. 3436-3439, 2020.

[31]A. N. Tarasova, "Effect of Reagent Concentrations on Equilibria in Water-Soluble Complexes," International Journal of Pharmaceutical Research, vol. 12, Supplementary Issue 2, pp. 1169-1172, 2020.
[32]A. N. Tarasova, "Effect of Vibration on Physical Properties of Polymeric Latexes," International Journal of Pharmaceutical Research, vol. 12, Supplementary Issue 2, pp. 1173-1180, 2020.

[33] V. A. Pogodin, L. N. Rabinskii, S. A. Sitnikov, "3D Printing of Components for the Gas-Discharge Chamber of Electric Rocket Engines," Russian Engineering Research, vol. 39, no. 9. pp. 797-799, 2019.

[34] Y. K. Kyaw, E. L. Kuznetsova, A. V. Makarenko, "Complex mathematical modelling of mechatronic modules of promising mobile objects," INCAS Bulletin, 12(Special Issue), pp. 91-98, 2020.

[35] Y. K. Kyaw, P. F. Pronina, P. O. Polyakov, "Mathematical modelling of the effect of heat fluxes from external sources on the surface of spacecraft," Journal of Applied Engineering Science, 18(4), pp. 732-736, 2020.

[36]M. O. Kaptakov, "Effect of Thin Polymer Layers on Mechanical Properties of Metal Surfaces," Turkish Journal of Computer and Mathematics Education (TURCOMAT), vol. 12, no. 5, pp. 525-529, 2021.

[37] M. O. Kaptakov, "Modelling of Mechanical Properties of Metal Plates with Polymer Coatings," Turkish Journal of Computer and Mathematics Education (TURCOMAT), vol. 12, no. 5, pp. 530-534, 2021.

[38]L. N. Rabinskiy, O. V. Tushavina, V. F. Formalev, "Mathematical modeling of heat and mass transfer in shock layer on dimmed bodies at aerodynamic heating of aircraft," Asia Life Sciences, (2), pp. 897-911, 2019.

[39]N. A. Kucheva, V. Kohlert, "Mathematical modeling methods for estimation the thermophysical properties of heat-protective composite materials," Turkish Journal of Computer and Mathematics Education (TURCOMAT), vol. 12, no. 10, pp. 1606-1612, 2021.

[40]N. A. Kucheva, "Investigation of the mechanical properties of heat-protective highly porous composite materials using the effective medium model," Turkish Journal of Computer and Mathematics Education (TURCOMAT), vol. 12, no. 10, pp. 1613-1621, 2021.

[41]N. A. Kucheva, V. Kohlert, "Analytical solution of the problem of thermoelasticity for a plate heated by a source with a constant heat supply on one surface," Turkish Journal of Computer and Mathematics Education (TURCOMAT), vol. 12, no. 10, pp. 1622-1633, 2021.

[42] L. N. Rabinskiy, O. V. Tushavina, E. I. Starovoitov, "Study of thermal effects of electromagnetic radiation on the environment from space rocket activity," INCAS Bulletin, 12 (Special Issue), pp. 141-148, 2020.

[43] O. V. Egorova, Y. K. Kyaw, "Solution of inverse nonstationary boundary value problems of diffraction of plane pressure wave on convex surfaces based on analytical solution," Journal of Applied Engineering Science, 18(4), pp. 676-680, 2020.

[44]I. P. Lifanov, A. N. Astapov, V. S. Terentieva, "Deposition of heat-resistant coatings based on the $\mathrm{ZrSi} 2-$ MoSi2-ZrB2 system for protection of non-metallic composite materials in high-speed high-enthalpy gas flows," Journal of Physics: Conference Series, vol. 1713, no. 1, pp. 012025, 2020. 
[45]M. O. Kaptakov, "Investigation of Effective Mechanical Characteristics of Nanomodified Carbon-Epoxide Composite by Numerical and Analytical Methods," Turkish Journal of Computer and Mathematics Education (TURCOMAT), vol. 12, no. 5, pp. 535-541, 2021.

[46]M. O. Kaptakov, "Obtaining of Carbon Fibers Based Composite Materials and Study of Their Mechanical Properties," Turkish Journal of Computer and Mathematics Education (TURCOMAT), vol. 12, no. 10, pp. 1601-1605, 2021.

[47]I. P. Lifanov, A. A. Yurishcheva, A. N. Astapov, "Hightemperature protective coatings on carbon composites," Russian Engineering Research, vol. 39, no. 9, pp. $804-$ 808. 2019.

[48]N. A. Bulychev, A. V. Ivanov, "Effect of vibration on structure and properties of polymeric membranes," International Journal of Nanotechnology, vol. 16, nos. 6/7/8/9/10, pp. $334-343,2019$.

[49] N. A. Bulychev, A. V. Ivanov, "Nanostructure of OrganicInorganic Composite Materials Based on Polymer Hydrogels," International Journal of Nanotechnology, vol. 16, nos. 6/7/8/9/10, pp. $344-355,2019$.

[50] N. A. Bulychev, A. V. Ivanov, "Study of Nanostructure of Polymer Adsorption Layers on the Particles Surface of Titanium Dioxide," International Journal of Nanotechnology, vol. 16, nos. 6/7/8/9/10, pp. $356-365$, 2019.

[51] A. N. Astapov, I. P. Lifanov, M. V. Prokofiev, "Hightemperature interaction in the $\mathrm{ZrSi} 2-\mathrm{ZrSiO} 4$ system and its mechanism," Russian Metallurgy (Metally), no. 6, pp. $640-646,2019$.

[52]N. A. Bulychev, E. L. Kuznetsova, "Ultrasonic Application of Nanostructured Coatings on Metals," Russian Engineering Research, 39 (9), pp. 809-812, 2019.

[53] N. A. Bulychev, V. V. Bodryshev, L. N. Rabinskiy, "Analysis of geometric characteristics of two-phase polymer-solvent systems during the separation of solutions according to the intensity of the image of micrographs," Periodico Tche Quimica, 16(32), pp. 551559, 2019.

[54] S. A. Kolesnik, N. A. Bulychev, "Numerical analytic method for solving the inverse coefficient problem of heat conduction in anisotropic half-space," Journal of Physics: Conference Series, 1474(1), 012024, 2020.

[55] V. F. Formalev, N. A. Bulychev, S. A. Kolesnik, M. A. Kazaryan, "Thermal state of the package of cooled gasdynamic microlasers," Proceedings of SPIE - The International Society for Optical Engineering, 11322, article number 113221B, 2019.

[56] G. A. Kalugina, A. V. Ryapukhin, "Impact of the 2020 Pandemic on Russian Aviation," Russian Engineering Research, vol. 41. no. 7, pp. 627-630, 2021.

[57]R. N. Zaripov, I. M. Murakaev, A. V. Ryapukhin, "Development of the Organization's Key Performance Indicators System in Order to Improve the Effectiveness of Its Human Capital and Risk Management," TEM Journal, vol. 10, no. 1, pp. 298-302, 2021.
[58]N. A. Bulychev, L. N. Rabinskiy, O. V. Tushavina, "Effect of intense mechanical vibration of ultrasonic frequency on thermal unstable low-temperature plasma," Nanoscience and Technology: An International Journal, 11 (1), pp. 15-21, 2020.

[59]N. A. Bulychev, L. N. Rabinskiy, "Ceramic Nanostructures Obtained by Acoustoplasma Technique," Nanoscience and Technology: An International Journal, 10 (3), pp. 279-286, 2019.

[60]A. A. Kalugin, G. A. Kalugina, A. V. Ryapukhin, "Informational Support for the Sale of Passenger Aircraft," Russian Engineering Research, vol. 41, no. 2, pp. 183-187, 2021.

[61]R. N. Zaripov, I. M. Murakaev, S. V. Novikov, A. V. Ryapukhin, "Corporate Structure for Innovative Enterprises," Russian Engineering Research, vol. 40, no. 2, pp. 137-139, 2020.

[62] A. Y. Burova, "Concept of multistage discrete fourier transform without performing multiplications" Journal of Physics: Conference Series, vol. 1889, no. 2, 022003, 2021.

[63] A. Burova, "Reducing the Error of Digital Algorithms for Deductive Signal Processing Based on Their Multi-Stage Discrete Fourier Transform by the Difference Digital Filters," 22th International Conference on Digital Signal Processing and its Applications, DSPA 2020, no. 9213275, 2020.

[64] A. Y. Burova, "Minimization of asymmetry of thrust of dual-flow turbojet engines of airliner in accordance with the results of system analysis of thrust parameters," Asia Life Sciences, no. 2, pp. 629-643, 2019.

\section{Sources of Funding for Research Presented in a Scientific Article or Scientific Article Itself}

This work was supported by the Russian Foundation for Basic Research (RFBR), projects № 19-08-01023a and 20-0800707.

\section{Creative Commons Attribution License 4.0 (Attribution 4.0 International, CC BY 4.0)}

This article is published under the terms of the Creative Commons Attribution License 4.0

https://creativecommons.org/licenses/by/4.0/deed.en_US 